\title{
Vasoactive substances in the interstitium of contracting skeletal muscle examined by microdialysis
}

\author{
J. Bangsbo \\ Copenhagen Muscle Research Centre, The August Krogh Institute, LHF, Universitetsparken 13, DK-2100 Copenhagen Ø, \\ Denmark
}

\begin{abstract}
In the study of the regulation of skeletal muscle blood flow during exercise it is useful to obtain information regarding the concentrations of vasoactive substances in the muscle interstitium, a site where the compounds act on the vascular and skeletal muscle cells. The microdialysis technique is a useful tool for measuring interstitial substances in the muscle at rest and during exercise in human subjects, and the technique can also be used to study the effect of both systemic and local interventions in a specific area of an exercising muscle. Probe recovery, which represents the relative amount of a substance that is diffusing to the dialysis membrane, changes from rest to exercise and can be determined by the internal-standard technique which allows for a relatively high time resolution (min). Furthermore, the use of electrodes at the microdialysis outlet makes it possible to perform continuous measurements of interstitial substances. The present review gives examples of how the microdialysis technique has been applied to study potentially important vasodilators such as adenosine, $\mathrm{NO}$ and $\mathrm{K}^{+}$in human skeletal muscles and highlights areas for future research to establish the functional importance of these compounds.
\end{abstract}

Adenosine: Nitric oxide: Potassium: pH: Exercise

In skeletal muscle the balance between $\mathrm{O}_{2}$ demand and blood flow is closely regulated, with a linear relationship between work intensity and $\mathrm{O}_{2}$ delivery (Roach et al. 1999). It has been proposed that this precise regulation of blood flow involves locally produced or released vasoactive substances such as $\mathrm{K}^{+}$, protons, adenosine and NO. Traditionally, vasoactive substances have been determined in venous blood draining the active muscles. However, the concentration of such compounds in the venous blood may not represent the concentration in the muscle interstitium, which is the site where the vasoactive compounds act on the vascular and muscle cells. For example, although adenosine is produced in contracting skeletal muscles, in human subjects the concentration of adenosine in blood is very low and often non-detectable, as adenosine is rapidly taken up by the erythrocytes. In the present review, determinations of vasoactive substances in the muscle interstitium during exercise, using the microdialysis technique, will be discussed, focusing mainly on studies with human subjects. The basic principles of the microdialysis technique have been described and discussed by Arner (1999) and Henriksson (1999). Thus, only aspects of using the technique during exercise will be considered in the present review.

\section{Determination of microdialysis recovery during exercise}

The microdialysis technique can be used to determine interstitial concentrations of substances. If the microdialysis technique is used during non-equilibrium conditions, however, it must be known to what extent the substance investigated diffuses from the muscle interstitium to the microdialysis membrane. This factor is termed the probe recovery $(\mathrm{r})$, which is defined as:

$$
\mathrm{r}=\mathrm{c}_{\mathrm{d}} / \mathrm{c}_{\mathrm{i}}
$$

where $c_{d}$ and $c_{i}$ are the dialysate and interstitial concentrations respectively of the compound investigated. To avoid drainage of the interstitium, the perfusate often contains substances, and in particular the compound of interest, in concentrations similar to those of human blood. In all the experiments described in this review the perfusion medium was a Ringer-acetate buffer to which various compounds 
were added. If the perfusate contains the compound in a concentration $c_{p}$, probe recovery is termed relative recovery (rr) and can be calculated as:

$$
\mathrm{rr}=\mathrm{c}_{\mathrm{d}}-\mathrm{c}_{\mathrm{p}} / \mathrm{c}_{\mathrm{i}}-\mathrm{c}_{\mathrm{p}}
$$

and thus, $\mathrm{c}_{\mathrm{i}}$ can be calculated as:

$$
c_{i}=\left(c_{d}-c_{p} / r r\right)+c_{p}
$$

A number of approaches have been used to estimate recovery (for review, see Henriksson, 1999). However, in the present review only two methods which have been used in contracting muscle will be considered. In the no-net-flux method each microdialysis probe is perfused with different concentrations of the compound of interest, and recovery is estimated from the relationship between perfusate and dialysate concentrations (see Rosdahl et al. 1993). Hours of calibration are required before starting an experiment, and a major assumption is that the interstitial concentration of the compound investigated remains constant during the calibration period. Furthermore, the procedure can only be conducted at rest, and for use during exercise it has to be assumed that recovery during exercise is the same as at rest, which appears not to be the case (see below). Thus, the method is not well suited for investigations in contracting muscles.

Recovery of a substance may be determined by the use of a marker substance which is infused either systemically or within the perfusate (Larsson, 1991; Scheller \& Kolb, 1991; Lønnroth \& Strindberg, 1995). This method is referred to as the internal-standard technique, or sometimes retrodialysis or relative loss. The assumption is that the recovery marker has similar diffusion properties to those of the substance sampled from the interstitium, i.e. the relative loss of the marker from the perfusate is equal to the recovery of the compound of interest. The marker substance is most commonly a radioactively-labelled analogue of the substance of interest, e.g. $\left[{ }^{14} \mathrm{C}\right]$ glucose when interstitial glucose is investigated.

Evaluation of the internal-standard technique can easily be made in vitro, as will be described using glucose as an example. Glucose is added to a medium surrounding the microdialysis probe and the probe is perfused with a perfusate containing $\left[{ }^{14} \mathrm{C}\right]$ glucose. The dialysate is collected and the glucose concentration in the perfusate, medium and dialysate is measured. The activity of $\left[{ }^{14} \mathrm{C}\right]$ glucose in the perfusate and dialysate is measured using a liquidscintillation counter. From the glucose measurement it is possible to estimate the relative recovery for glucose as described previously, which can be compared with the recovery determined by the internal-standard technique termed relative loss ( $\mathrm{rl}$ ) and estimated as:

$$
\mathrm{rl}=\mathrm{P}_{\mathrm{dpm}}-\mathrm{D}_{\mathrm{dpm}} / \mathrm{P}_{\mathrm{dpm}}
$$

where $P_{d p m}$ and $D_{d p m}$ represent the activities of the labelled analogue of the compound investigated, expressed in disintegrations per $\min (\mathrm{dpm})$, for the perfusate and dialysate respectively. Fig. 1 shows an example of such a comparison at different rates of perfusate flow with the

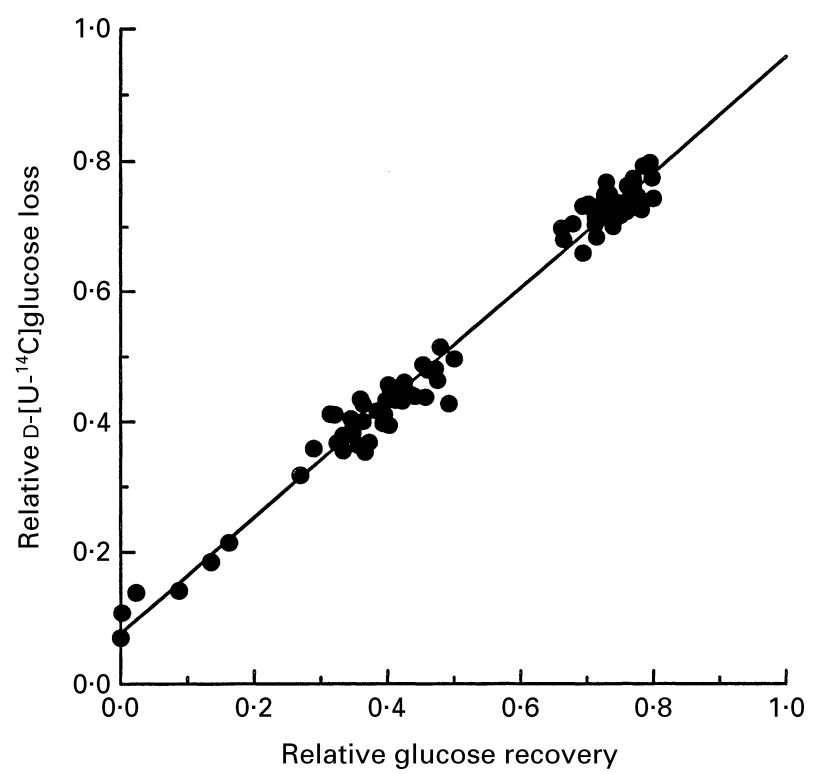

Fig. 1. Relationship between microdialysis in vitro determination of recovery of glucose directly $(x)$ and determination of recovery of glucose by the internal-standard technique using $\left[U-{ }^{14} \mathrm{C}\right]$ glucose $(y)$. The relationship is described by the equation $y=0.88 x+0.08(r 0.99$, $P<0.001)$.

concentrations of glucose in the perfusate and medium being 3.0 and $1.5 \mathrm{mmol} / 1$ respectively. The concentration of glucose in the perfusate and medium can be varied to enable a further examination.

It is difficult to evaluate the microdialysis methods in vivo since no 'gold standard' exists. One approach, however, for examining the method is to compare the values obtained with data obtained at a very low perfusion rate that may give approximately $100 \%$ recovery. This method was used in an attempt to evaluate the internal-standard technique in vivo during rest and recovery. Probes were perfused at rates of both 0.5 and $5.0 \mu \mathrm{l} / \mathrm{min}$. Relative losses of lactate during the low and high perfusion rates were 0.81 (SE 0.20) and 0.21 (SE 0.01) at rest $(n 15)$ respectively, and 0.97 (SE 0.01) and 0.38 (SE 0.01) during exercise $(n 5 ; 10 \mathrm{~W})$ respectively. The estimated mean lactate concentrations at rest were $4.4(\mathrm{SE} 0.8)$ and $4.6(\mathrm{SE} 0.8) \mathrm{mmol} / \mathrm{l}$ at the low and high perfusion rates respectively, and the corresponding values during exercise were 4.2 (SE 1.2) and 5.0 (SE 1.3) $\mathrm{mmol} / \mathrm{l}$ respectively. A positive correlation between the two determinations was obtained both at rest and during exercise, but the values were scattered (Fig. 2). One explanation may be that the concentration of the investigated compound in the interstitium is not constant during the evaluation procedure (approximately $2 \mathrm{~h}$ ), which is one of the limitations of this type of evaluation.

Due to a considerable variation in recovery between probes, recovery needs to be determined for each probe (Fig. 3). The internal-standard technique has the advantage that it detects changes in the property of a probe throughout an experiment, when measurements of the tracer are made on the same dialysate sample as that used for the other analysis. Thus, that recovery can be determined even when the rate of perfusion is lower than expected. However, in the 

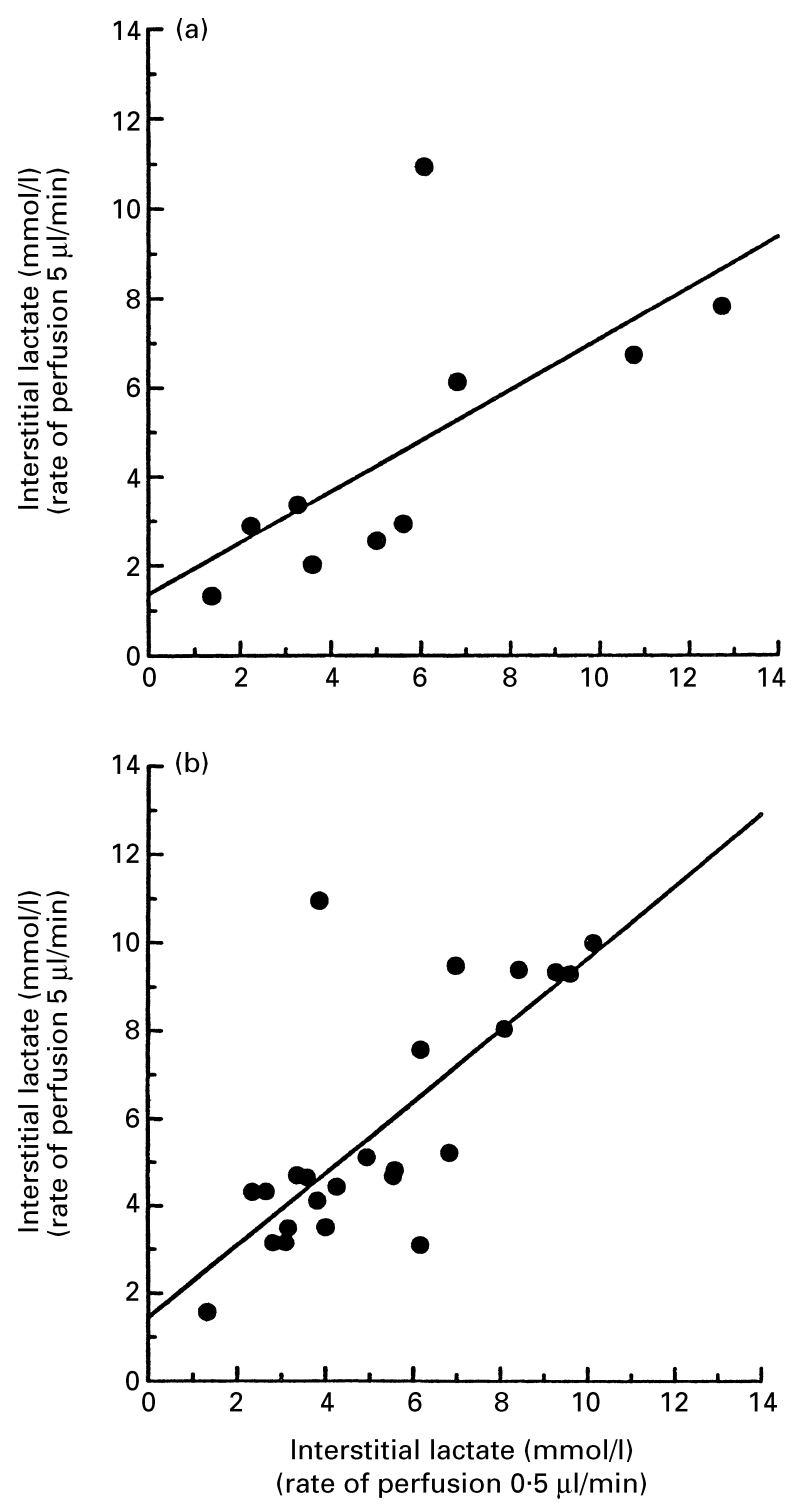

Fig. 2. Estimated muscle interstitial concentrations of lactate using a perfusion rate of $0.5 \mu \mathrm{l} / \mathrm{min}(x)$ in relation to the estimated muscle interstitial concentration of lactate using a perfusion rate of $5 \mu \mathrm{l} / \mathrm{min}(y)$ : (a) during knee-extensor exercise (10 W; $y=0.58 x+1.39 ; r 0.768$, $P<0.005)$ and (b) at rest $(y=0.61 x+1.18 ; r 0.643, P<0.1)$.

experiments described later only probes in which the perfusion rate was within a $10 \%$ range of the expected were used.

A common finding is that recovery, determined using the internal-standard technique, is elevated during exercise (Fig. 4; McLean et al. 1999). It is unclear what causes this increase, but it may be that muscle contraction causes a greater mixing of the muscle interstitium and thereby better diffusion.

\section{Effect of microdialysis probe insertion}

One concern with the microdialysis technique is that it may damage the surrounding tissue. The effect of probe insertion has been examined mainly in rat brain or human skin, and such studies have shown an initial effect that disappears

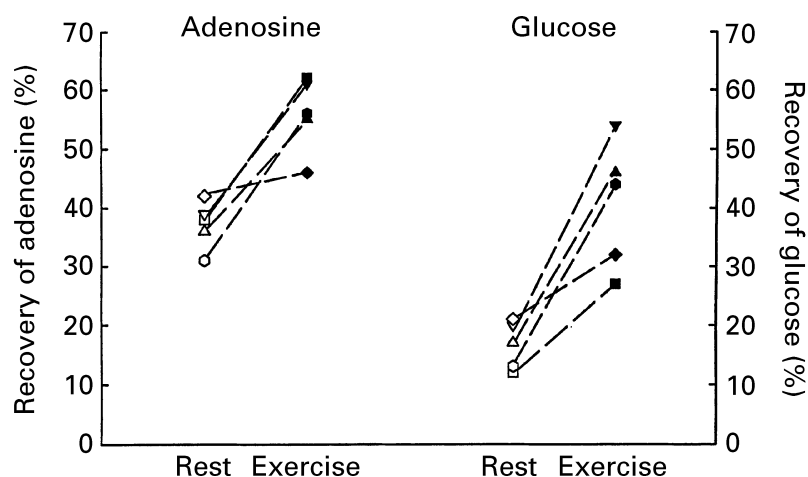

Fig. 3. Recovery of adenosine and glucose determined using microdialysis probes positioned in different areas of $m$. vastus lateralis of a subject at rest $(\diamond, \nabla, \square, \triangle, \bigcirc)$ and during knee-extensor exercise at $30 \mathrm{~W}(\bullet, \nabla, \mathbf{\square}, \mathbf{\Delta}, \bullet)$.

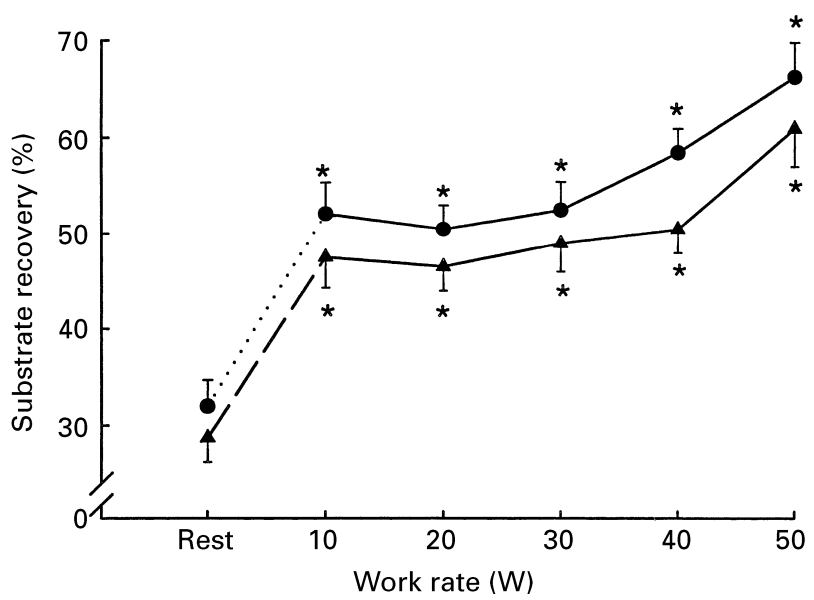

Fig. 4. Recovery of glucose $(\bullet)$ and lactate $(\boldsymbol{\Delta})$ in microdialysis probes positioned in $\mathrm{m}$. vastus lateralis during knee-extensor exercise at various intensities. Values are means with their standard errors represented by vertical bars for $n 10-30$ determinations. Mean values were significantly different from those at rest: ${ }^{*} P<0 \cdot 05$. (Data from McLean et al. 1999.)

after a period of time (h; Benveniste \& Hansen, 1991; Anderson et al. 1994). Histological examinations of rat skeletal muscles at 1, 6, 12 and $32 \mathrm{~h}$ after insertion did not show any evidence of bleeding or pockets of extracellular fluid around the microdialysis probes (Palsmeier \& Lunte, 1994). Furthermore, no morphological changes in the tissues were documented, and probe recovery was constant for $24 \mathrm{~h}$ despite observations of lymphocyte infiltration beginning at $6 \mathrm{~h}$ and continuing over the next $24 \mathrm{~h}$. An indirect way of determining damage by insertion of the microdialysis probe is by measuring compounds that may be affected by cell rupture. $\mathrm{K}^{+}$may serve such a purpose since it is expected that $\mathrm{K}^{+}$concentration would be high if muscle or blood cells are damaged. In experiments with human subjects, dialysate $\mathrm{K}^{+}$concentrations were measured for $2 \mathrm{~h}$ after probe insertion. After an initial high concentration the $\mathrm{K}^{+}$concentration reached a constant level of approximately $3.8 \mathrm{mmol} / \mathrm{l}$ after about $20 \mathrm{~min}$ (Fig. 5). This finding suggests that following an initial phase after probe insertion the tissue is stabilized. In the experiments referred to later no measurements were performed in the first $90 \mathrm{~min}$ after probe 
insertion. It should be emphasized that the measurement of $\mathrm{K}^{+}$concentrations is an indirect evaluation of damage, and it does not exclude leakage of substances when the muscle cells are contracting. On the other hand, the observation that the concentrations of compounds like $\mathrm{K}^{+}$and adenosine increase in relation to exercise intensities, even when performed in random order, suggests that any effect of damage on the interstitial concentrations is small (Hellsten et al. 1998). Furthermore, passive movements do not significantly change the concentrations of compounds like $\mathrm{K}^{+}$and lactate, suggesting that lengthening and shortening of a muscle does not lead to leakage of substances. Nevertheless, more work needs to be done to investigate whether damage occurs on insertion of the probes and during contractions.

\section{Using microdialysis during exercise}

There are a number of methodological considerations that need to be made before performing an experiment using the microdialysis technique.

The size of the pores in the microdialysis membrane should of course be large enough for the compound of interest to move into the membrane. In the experiments described later membranes with either an effective pore size of 5000 (home-made) or 20000 (CMA60; CMA, Stockholm, Sweden) Da have been used, which is sufficient to allow substances like adenosine (267 Da), lactate (89 Da), glucose $(180 \mathrm{Da})$ and $\mathrm{K}^{+}(39 \mathrm{Da})$ to diffuse from interstitium to the membrane. It should be noted that the size of the pores is probably not the only factor that determines the diffusion of the compound into the membrane. For example, an in vivo comparison performed in resting muscle showed that recovery of adenosine (approximately $37 \%$ ) was higher than the recovery of lactate and glucose (approximately $25 \%$ ), although adenosine is larger in size than both lactate and glucose.

The length of the microdialysis membrane can be varied. The longer the membrane the greater the recovery. However, the membrane must not be longer than will allow it to be positioned entirely in the muscle without causing

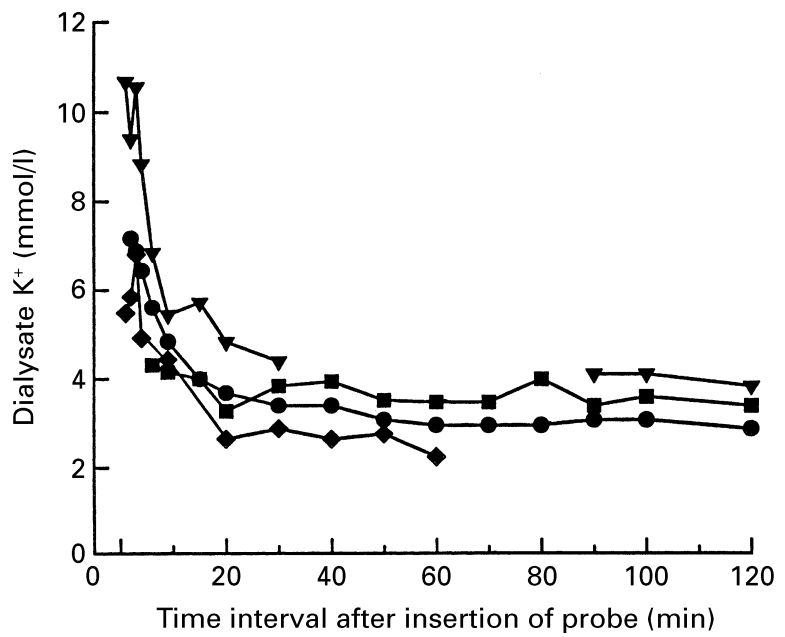

Fig. 5. Dialysate potassium concentration determined in dialysate after insertion of four microdialysis probes positioned in $m$. vastus lateralis of one subject. damage. In studies with human subjects we have used home-made probes with a membrane length of $40 \mathrm{~mm}$ or commercially-available probes with membranes $30 \mathrm{~mm}$ long (CMA60).

The rate of perfusion is another important factor to take into consideration when performing an experiment. If determination of recovery is not a requirement, a very low perfusion rate may be used in which equilibrium between muscle interstitium and the probe may be obtained. For example, Rosdahl et al. (1998) observed that at a flow rate of $0.16 \mu \mathrm{l} / \mathrm{min}$ the dialysate concentration of glucose was almost equal to the venous glucose concentration, and suggested that full recovery was achieved. However, it cannot be excluded that a difference between the interstitial and venous concentrations existed. At the perfusion rate of $0 \cdot 16 \mu \mathrm{l} / \mathrm{min}$ a marked difference between plasma and dialysate lactate was observed. Thus, the perfusion rate needs to be even lower than $0 \cdot 16 \mu \mathrm{l} / \mathrm{min}$ to achieve full recovery for lactate and perhaps glucose. A low perfusion rate has the disadvantage that it takes a long time to obtain a sufficient amount of dialysate for analysis, which is a particular problem during exercise, as it means that only low-intensity exercise can be studied.

In order to achieve a high time resolution and a sufficient amount of dialysate during more-intense exercise where the duration of the exercise is limited, the perfusion rate has to be relatively high during exercise. This is also the case when changes in the muscle interstitium are to be examined, e.g. in the transition from rest to exercise. However, the higher the perfusion rate the smaller the recovery, which makes the determination of the interstitial concentration more insensitive. This factor is illustrated in Fig. 6, in which recoveries determined in vitro at perfusion rates of 2 and $5 \mu \mathrm{l} / \mathrm{min}$ are compared. Thus, the perfusion rate used during exercise is a balance between a high time resolution and obtaining a sufficient recovery of the compound of interest. It is also dependent on the amount of fluid needed to do the analysis. For example, with modern equipment glucose concentration

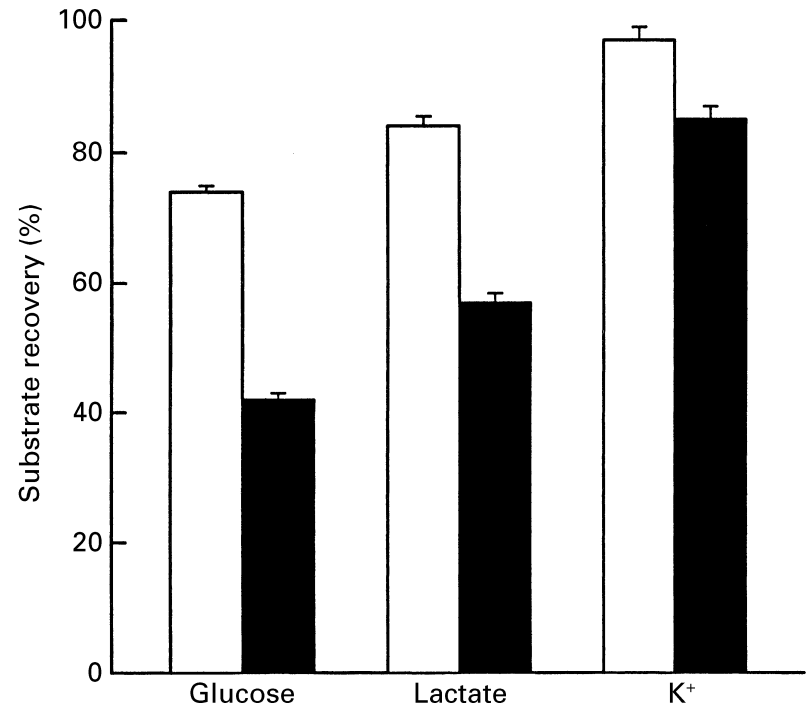

Fig. 6. Recovery of glucose, lactate and potassium determined in vitro at a perfusion rate of $2(\square)$ and $5(\square) \mu \mathrm{l} / \mathrm{min}$. Values are means with their standard errors represented by vertical bars for $n 15$ determinations. 
can be measured in less than $1 \mu \mathrm{l}$ provided that the concentration is not very low, whereas determination of adenosine often requires more than $20 \mu \mathrm{l}$. Thus, the time resolution can be at least 20-fold higher for glucose than for adenosine, or the flow rate can be lower when glucose is studied. In most of the experiments presented later a perfusion rate of $5 \mu \mathrm{l} / \mathrm{min}$ was used.

If rapid changes in concentrations are to be examined, the time for the perfusate to move from the end of the microdialysis membrane to the point of collection or measurement has to be taken into account. The time taken depends on the volume of the tubing at the probe outlet. For a CMA60 microdialysis probe the time delay is about $45 \mathrm{~s}$. To study recovery immediately after exercise with such a probe, therefore, collection of dialysate should be delayed more than $45 \mathrm{~s}$ after exercise to ensure that there is not a contribution of interstitial fluid from the exercise period. The problem is not as pronounced when the compound, e.g. $\mathrm{K}^{+}$, is measured with an electrode positioned in the dialysate, since the transition between different periods, such as rest and exercise as well as exercise and recovery, is measured continuously.

\section{Determination of local blood flow in vivo}

A marked spatial heterogeneity has been observed in skeletal muscle of animals in studies using radioactivelylabelled microspheres (Laughlin \& Armstrong, 1982; Piiper et al. 1985; Iversen \& Nicolaysen, 1989; Iversen et al. 1989), indicating regional differences in perfusion. To study such differences and examine the local effect of various vasoactive substances using the microdialysis technique, a method for the determination of blood flow in a small region of a muscle would be required.

In recent years a microdialysis method using ethanol has been developed to study local blood flow. Ethanol, which has been suggested to be metabolically inert in the muscle, is added to the perfusate and the ratio ethanol measured in the outflow (dialysate) : ethanol in the inflow (perfusate) has been proposed to be inversely correlated with the blood flow (Hickner et al. 1992, 1995). The microdialysis ethanol method has been validated against a ${ }^{133} \mathrm{Xe}$-clearance method in rat skeletal muscle (Hickner et al. 1994). However, the ${ }^{133} \mathrm{Xe}$-clearance method is known to show a non-linear response and to have inherent methodological limitations, such as differences in tissue tracer solubility (Clausen \& Lassen, 1971; Lassen et al. 1983). In order to evaluate the ethanol method in vivo, a study was recently performed in which blood flow to a leg was increased by arterial infusion of adenosine both at rest and during exercise. At rest, leg blood flow was elevated from 0.16 to 1.80 litres/min with adenosine infusion without any change in the ethanol outflow: inflow determined in probes inserted in $m$. vastus lateralis (Fig. 7). During exercise, ethanol outflow : inflow decreased, but it was unchanged with arterial infusion of adenosine, leading to an increase in blood flow from 3.79 to 6.13 litres/min (Fig. 7). Thus, it appears that the ethanol outflow : inflow does not represent changes in muscle blood flow. It was also observed that the recoveries of glucose and adenosine were unaltered during arterial adenosine infusion both at rest and during exercise, but recoveries of both
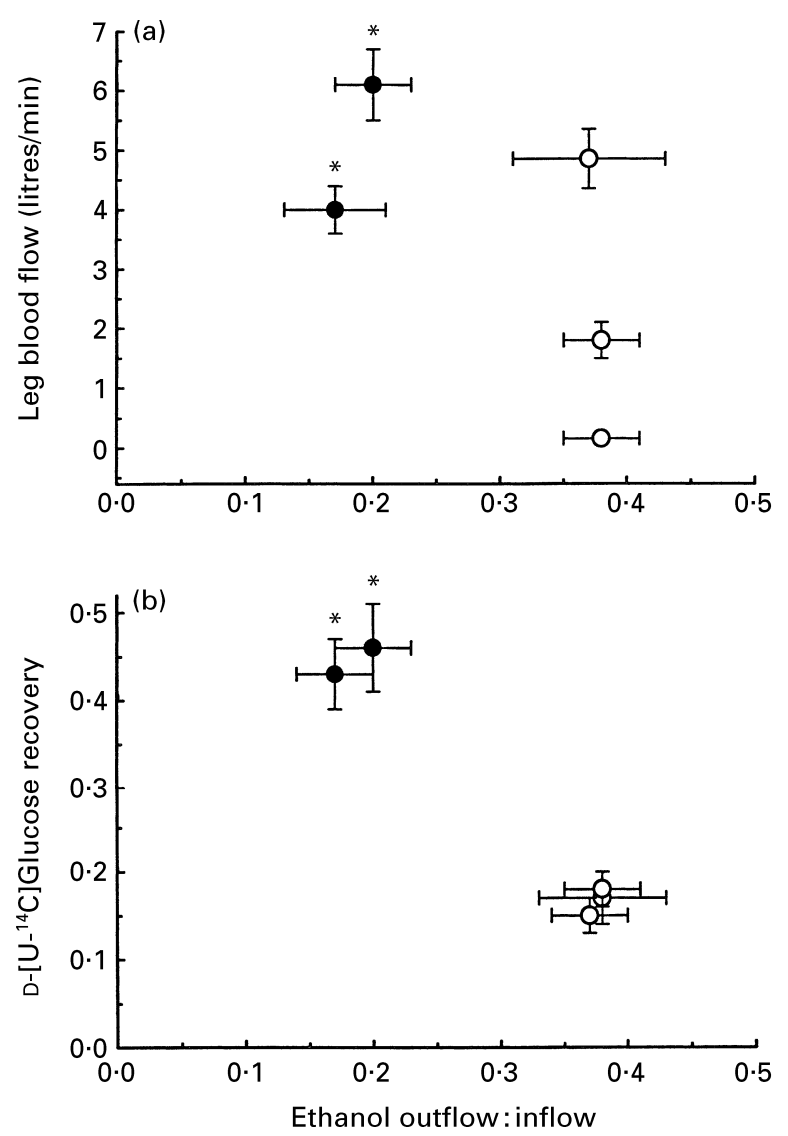

Fig. 7. Dialysate: perfusate ethanol (probes positioned in different areas of $m$. vastus lateralis) and (a) leg blood flow measured by the thermodilution technique (Anderson \& Saltin, 1985) and (b) glucose recovery (using $\left[\mathrm{U}-{ }^{14} \mathrm{C}\right]$ glucose) with and without arterial infusion of adenosine at rest $(\bigcirc)$ and during knee-extensor exercise $(\bullet)$. Values are means with their standard errors represented by vertical bars for $n 22$ determinations. Mean values were significantly different from those at rest: ${ }^{\star} P<0.05$. (Data from Rådegran et al. 1998.)

increased from rest to exercise (Fig. 7). Thus, changes in ethanol removal from the probes may reflect contractioninduced changes in probe recovery rather than changes in local blood flow. It is clear that further work is needed to develop a method that will allow determinations of local blood flow.

\section{Vasoactive substances in the muscle interstitium during exercise}

A number of studies performed to determine the interstitial concentrations of $\mathrm{NO}$, adenosine and $\mathrm{K}^{+}$as well as the interplay between the compounds are presented in this section. In addition, the potential importance of these substances in blood-flow regulation will be discussed briefly.

NO is a strong vasodilator (Vallence et al. 1989; Moncada, 1992), and it may play an important role in the regulation of muscle blood flow during exercise (Stein et al. 1998). The enzyme producing NO (nitric-oxide synthase; EC 1.4.13.39) is present in both muscle and endothelial cells (Frandsen et al. 1996), and it has been observed that the degradation products nitrate and nitrite are elevated in 
dialysate from contracting skeletal muscle (U Frandsen, J Bangsbo, JJ Nielsen and Y Hellsten, unpublished results). However, as recovery rates of nitrate and nitrite were not determined, it cannot be excluded that the higher concentration in the dialysate was due to a higher recovery of these substances during exercise. On the other hand, NO has recently been determined directly in the microdialysis outlet during rest, exercise and recovery, and a marked increase was observed during exercise (U Frandsen, J Bangsbo, JJ Nielsen and Y Hellsten, unpublished results). This finding clearly suggests that NO is produced in the exercising muscles, since a very high recovery is to be expected even at rest, since NO is a dissolved gas which easily passes through membranes. Recent studies have focused on the functional role of $\mathrm{NO}$ in human skeletal muscle by using $N^{\mathrm{G}}$-monomethyl-L-arginine, an inhibitor of nitric-oxide synthase (Rådegran \& Saltin, 1997). When the inhibitor was administered, a significant decrease in blood flow was observed at rest and during recovery from exercise, but not during exercise. Thus, NO appears to be of importance for blood flow at rest and recovery, whereas its role during exercise is unclear.

Adenosine is an active vasodilator substance, as is clear also from the study with arterial infusion of adenosine described earlier (Dobson et al. 1971; Rådegran et al. 1998). By use of the microdialysis technique and $\left[2-{ }^{3} \mathrm{H}\right]$ adenosine to determine recovery, adenosine has been observed to increase in muscle interstitium during exercise in relation to exercise intensity (Fig. 8). Furthermore, the interstitial concentration of the substrate for adenosine, AMP, also increases during exercise, which may play an important role in the regulation of adenosine (Hellsten et al. 1998). It is unclear, however, to what extent the increase in adenosine affects muscle blood flow during exercise. One approach in future studies could be to block adenosine receptors and monitor the influence on muscle blood flow and local vasodilators using the microdialysis technique.

It is well known that adenosine mediates vasodilatation directly by action on the vascular smooth muscle cells

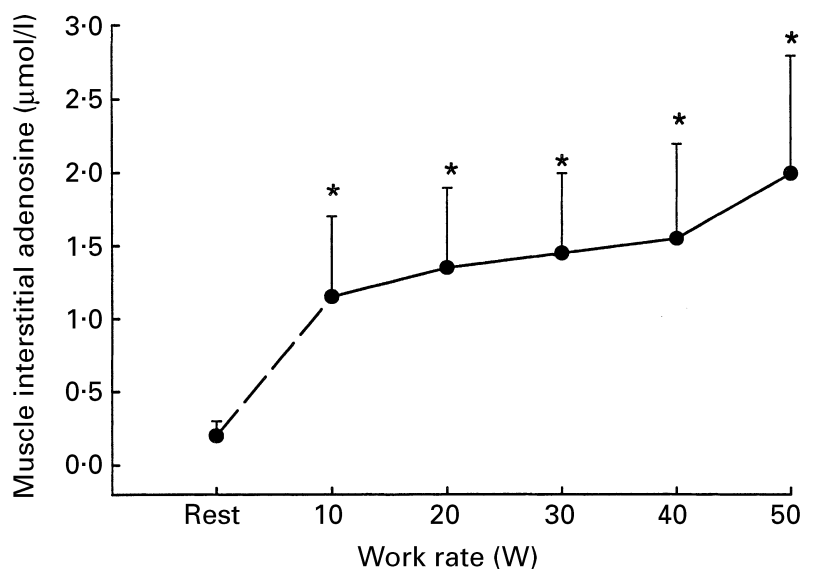

Fig. 8. Muscle interstitial adenosine concentration at various intensities of knee-extensor exercise measured using the microdialysis technique and $\left[2-{ }^{3} \mathrm{H}\right]$ adenosine. Values are means with their standard errors represented by vertical bars for $n 7$ determinations. Mean values were significantly different from those at rest: ${ }^{*} P<0.05$. (Data from Hellsten et al. 1998.) through cAMP-dependent mechanisms (Herlily et al. 1976). Based on studies on the hindlimb skeletal muscle of the rat during hypoxia, it has been proposed that adenosine, via activation of adenosine receptors, causes vasodilation through opening of muscle membrane $\mathrm{K}^{+}$channels, leading to an elevated level of interstitial $\mathrm{K}^{+}$which then causes the relaxation of the smooth muscle cells (Marshall et al. 1993). In addition, adenosine may also increase the NO production (Skinner \& Marshall, 1996). These issues were addressed by addition of AMP to the perfusate which diffuses through the microdialysis membrane into muscle interstitium. The probes were perfused with AMP, the precursor for adenosine, resulting in a pronounced increase in muscle interstitial adenosine concentration confirming the hypothesis that adenosine can be produced extracellularly from AMP by skeletal muscle cells (Hellsten \& Frandsen, 1997). The elevated levels of adenosine allowed an examination of the effect of adenosine on other potential vasoactive substances, namely $\mathrm{NO}$ and $\mathrm{K}^{+}$. The dialysate concentration of neither $\mathrm{NO}$ nor $\mathrm{K}^{+}$was altered when the adenosine concentration was elevated. Furthermore, in another study adenosine was infused into the femoral artery at rest and during exercise leading to pronounced elevation of blood flow, whereas no effect was found on the $\mathrm{K}^{+}$concentration in the dialysate from probes inserted in the leg being studied (Fig. 9). These findings suggest that the effect of adenosine is not exerted through $\mathrm{K}^{+}$and $\mathrm{NO}$ in human skeletal muscle.

It is well known that $\mathrm{K}^{+}$is released from exercising muscles (Juel et al. 1990). Furthermore, inhibition of ATP-sensitive $\mathrm{K}^{+}$channels with glibenclamide in the rat hindlimb during systemic hypoxia reduces $\mathrm{K}^{+}$efflux from the muscle and attenuates vasodilation (Marshall et al. 1993). It has also been observed that $\mathrm{K}^{+}$has an effect on smooth muscle cells, which can lead to vasodilation (Mian et al. 1990). In a few studies $\mathrm{K}^{+}$concentrations in the interstitium of contracting muscles have been reported (Hnik et al. 1972, 1976; Vyskoãl et al. 1983). However, it was not until recently that concentrations during concentric exercise at various intensities have been determined using

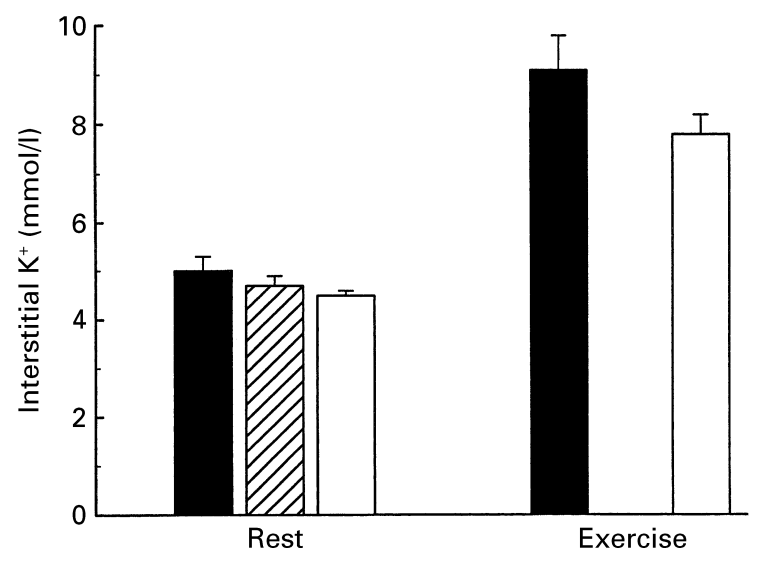

Fig. 9. Muscle dialysate potassium concentration before $(\boldsymbol{m})$ and after infusion of adenosine at low (שm) and high $(\square)$ concentrations (125 and $1000 \mu \mathrm{g} / \mathrm{min}$ per litre thigh volume respectively) in the femoral artery at rest and during exercise. Values are means with their standard errors represented by vertical bars for $n 22$ determinations. (Data from Rådegran et al. 1998.) 
the microdialysis technique. Recovery of $\mathrm{K}^{+}$cannot be determined by using labelled $\mathrm{K}^{+}$, since such tracer compounds are too short-lived. Instead, an isotope of $\mathrm{Tl}$, ${ }^{200} \mathrm{Tl}$, has been used for the determination of recovery, which appears to be reasonable since the molecule behaves similarly to $\mathrm{K}^{+}$(Nitsch et al. 1980). Furthermore, the relative loss of ${ }^{200} \mathrm{Tl}$ has been shown to reflect recovery of $\mathrm{K}^{+}$in vitro (Green et al. 1999). When using ${ }^{200} \mathrm{Tl}$ it was observed that the 'recovery of $\mathrm{K}^{+}$' increased from 0.47 at rest to 0.69 and 0.75 at 10 and $70 \mathrm{~W}$ knee-extensor exercise respectively (Juel et al. 1999). Furthermore, it was shown that the $\mathrm{K}^{+}$concentration increased with increasing exercise intensity. Measurements with $\mathrm{K}^{+}$electrodes at the probe outlet have made it possible to determine $\mathrm{K}^{+}$continuously. Fig. 10 shows an example of the change in dialysate $\mathrm{K}^{+}$in relation to different exercise intensities and recovery periods. It should be noted that the interstitial concentration of $\mathrm{K}^{+}$, in contrast to the concentration in venous blood draining the exercise muscle, remains high for a period after exercise ( $\mathrm{min}$ ) as is the case for blood flow (Bangsbo \& Hellsten, 1998). These studies show that $\mathrm{K}^{+}$has the potential to be an important vasodilator, but further studies are needed to clarify the functional role of the increase in $\mathrm{K}^{+}$in the muscle interstitium.

Low $\mathrm{pH}$ has been shown to lower the $\mathrm{Ca}^{2+}$ sensitivity of smooth muscle cells (see Smith et al. 1998). This factor is one of the reasons why $\mathrm{pH}$ in the muscle interstitium may play a role in the regulation of the local blood flow during exercise. Lactate formation in skeletal muscle leads to a production of protons, since lactate is almost entirely dissociated to lactate anion and $\mathrm{H}^{+}$. During exercise at low intensities the proton production does not lead to a decrease in muscle cell $\mathrm{pH}$ as the protons are either buffered within, or released from, the muscle cells. At high submaximal and supramaximal exercise, muscle cell $\mathrm{pH}$ decreases and the release of protons increases. The question is, to what extent does proton release from the muscle cells lead to a change in

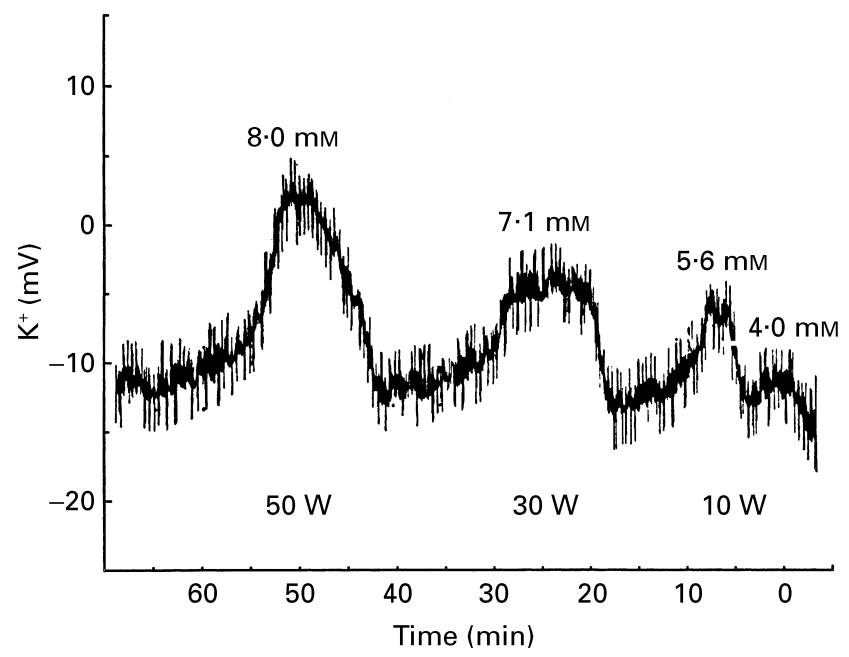

Fig. 10. Potassium determined before, during and after various intensities of knee-extensor exercise. The measurements were performed using a potassium electrode placed in dialysate from a microdialysis probe positioned in $m$. vastus lateralis. The estimated peak interstitial concentrations at each of the exercise intensities are also shown.
$\mathrm{pH}$ in interstitium of contracting muscle? Further studies using the microdialysis technique should address this important issue.

Low intracellular $\mathrm{pH}$ levels may also have an indirect effect on blood flow through elevation of muscle interstitial $\mathrm{K}^{+}$by increasing the opening of ATP-sensitive $\mathrm{K}^{+}$channels. It has been demonstrated in vitro that low $\mathrm{pH}(<6 \cdot 8)$ opens the channels leading to an elevation of the interstitial $\mathrm{K}^{+}$ concentration (Davies, 1992). Furthermore, the release of $\mathrm{K}^{+}$from contracting human skeletal muscles was higher when muscle $\mathrm{pH}$ was lowered (Bangsbo et al. 1996). Thus, muscle $\mathrm{pH}$ may be important in the regulation of muscle interstitial $\mathrm{K}^{+}$and blood flow.

\section{Summary}

In summary, the microdialysis technique is a useful tool for measuring muscle interstitial concentrations of vasoactive substances during exercise in human subjects. The technique can also be used to study the effect of both systemic and local interventions in a specific area of an exercising muscle. The traditional methods used to determine probe recovery cannot be applied to contracting muscles, since probe recovery changes from rest to exercise. Instead, very low perfusion rates in which full recovery has to be assumed may be used, but this approach can only be used at low-intensity exercise. The internal-standard technique to determine recovery will allow a higher time resolution ( $\mathrm{min}$ ), and recovery can be determined for every sampling period, allowing an exact estimation of the recovery for each probe. The use of electrodes allows for continuous measurements of interstitial ions.

The present review has also presented examples of how the microdialysis technique has been applied to study potentially important vasodilators in human skeletal muscles and highlighted areas of further research to establish the functional importance of the compounds.

\section{Acknowledgements}

The studies presented were supported by a grant from The Danish National Science Foundation (11-0082). In addition, support was obtained from The Danish Natural Science Foundation, The Danish Sport Research Council (Idrættens Forskningsråd) and Team Danmark. The studies presented were performed in collaboration with Ylva Hellsten, Jens Jung Nielsen, Henriette Pilegaard, Goran Rådegran, Ulrik Frandsen, Carsten Juel, Bengt Saltin and Dave McLean.

\section{References}

Anderson C, Andersson T \& Wårdell K (1994) Changes in skin circulation after insertion of a microdialysis probe visualized by laser Doppler perfusion imaging. Journal of Investigative Dermatology 102, 807-811.

Arner P (1999) Microdialysis: use in human exercise studies. Proceedings of the Nutrition Society 58, 913-917.

Anderson C \& Saltin B (1985) Maximal perfusion of skeletal muscle in man. Journal of Physiology 366, 233-249. 
Bangsbo J \& Hellsten Y (1998) Muscle blood flow and oxygen uptake in recovery from exercise. Acta Physiologica Scandinavica 162, 305-312.

Bangsbo J, Madsen K, Kiens B \& Richter EA (1996) Effect of muscle acidity on muscle metabolism and fatigue during intense exercise in man. Journal of Physiology 495, 587-596.

Benveniste H \& Hansen AJ (1991) Practical aspects of using microdialysis for determination of brain interstitial concentrations. In Microdialysis in the Neurosciences. Techniques in the Behavioral and Neural Sciences, vol. 7, pp. 81-100 [TE Robinson and JB Justice, editors]. Amsterdam: Elsevier.

Clausen J \& Lassen NA (1971) Muscle blood flow during exercise in normal man studied by the 133 Xenon clearance method. Cardiovascular Research 5, 245-254.

Davies NW (1992) ATP-dependent $\mathrm{K}^{+}$channels and other $\mathrm{K}^{+}$ channels of muscle: how exercise may modulate their activity. In Muscle Fatigue Mechanisms in Exercise and Training. Medicine in Sports and Science, vol. 34, pp. 1-10 [P Marconnet, PV Komi, B Saltin and OM Sejersted, editors]. Basel: Karger.

Dobson JG, Rubio R \& Berne RM (1971) Role of adenine nucleotides, adenosine and inorganic phosphate in the regulation of skeletal muscle blood flow. Circulation Research 29, 375-384.

Frandsen U, Lopez-Figueroa M \& Hellsten Y (1996) Localization of nitric oxide synthase in human skeletal muscle. Biochemical and Biophysical Research Communications 227, 88-93.

Green S, Bülow J \& Saltin B (1999) Muscle interstitial $\mathrm{K}^{+}$during rest and exercise in humans. Journal of Applied Physiology 87, 460-464.

Hellsten Y \& Frandsen U (1997) Adenosine formation in contracting primary rat skeletal muscle cells and endothelial cells in culture. Journal of Physiology 504, 695-704.

Hellsten Y, McLean D, Rådegran G, Saltin B \& Bangsbo J (1998) Adenosine concentrations in the interstitium of resting and contracting human skeletal muscle. Circulation 98, 6-8.

Henriksson J (1999) Microdialysis of skeletal muscle at rest. Proceedings of the Nutrition Society 58, 919-923.

Herlihy JH, Bockman EL, Herne RM \& Rubio R (1976) Adenosine relaxation of isolated vascular smooth muscle. American Journal of Physiology 230, 1239-1243.

Hickner RC, Bone D, Ungerstedt U, Jorfeldt L \& Henriksson J (1994) Muscle blood flow during intermittent exercise: comparison of the microdialysis ethanol technique and ${ }^{133} \mathrm{Xe}$ clearance. Clinical Science 86, 15-25.

Hickner RC, Ekelund U, Mellander S, Ungerstedt U \& Henriksson $\mathrm{J}$ (1995) Muscle blood flow in cats: comparison of microdialysis ethanol technique with direct measurements. Journal of Applied Physiology 79, 638-647.

Hickner RC, Rosdahl H, Borg I, Ungerstedt U, Jorfeldt L \& Henriksson J (1992) The ethanol technique of monitoring local blood flow changes in rat skeletal muscle: implications for microdialysis. Acta Physiologica Scandinavica 146, 87-97.

Hnik P, Holas M, Krekule I, Kñz N, Mejsnar J, Smiesko V, Ujec E \& Vyskoãl F (1976) Work-induced potassium changes in skeletal muscle and effluent venous blood assessed by liquid ionexchanger microelectrodes. Pflügers Archiv 406, 458-463.

Hnik P, Vyskoãl F, Kñz N \& Holas M (1972) Work-induced increase of extracellular potassium concentration in muscle measured by ion-specific electrodes. Brain Research 40, 559-562.

Iversen PO \& Nicolaysen G (1989) Heterogenous blood flow distribution within single skeletal muscles in the rabbit: role of vasomotion sympathetic nerve activity and effect of vasodilation. Acta Physiologica Scandinavica 137, 125-133.
Iversen PO, Standa M \& Nicolaysen G (1989) Marked regional heterogeneity in blood flow within skeletal muscle at rest and during exercise hyperaemia in the rabbit. Acta Physiologica Scandinavica 136, 17-28.

Juel C, Bangsbo J, Graham T \& Saltin B (1990) Lactate and potassium fluxes from skeletal muscle during intense dynamic knee-extensor exercise in man. Acta Physiologica Scandinavica 140, 147-159.

Juel C, Pilegård H, Nielsen JJ \& Bangsbo J (1999) Interstitial potassium in human skeletal muscle during and after dynamic exercise determined by microdialysis. American Journal of Physiology (In the Press).

Larsson CI (1991) The use of an 'internal standard' for control of the recovery in microdialysis. Life Science 49, PL73-PL78.

Lassen NA, Henriksen O \& Sejrsen P (1983) Indicator methods for measurements of organ and tissue blood flow. In Handbook of Physiology, section 2, The Cardiovascular System: Peripheral Circulation and Organ Blood Flow, vol. 3, part 1, pp. 21-63 [JT Shepherd, FM Abboud and SR Geiger, editors]. Bethesda, MD: American Physiological Society.

Laughlin MH \& Armstrong RB (1982) Muscular blood flow distribution patterns as a function of running speed in rats. American Journal of Physiology 12, H296-H306.

Lönnroth P \& Strindberg L (1995) Validation of the 'internal reference technique' for calibrating microdialysis catheters in situ. Acta Physiologica Scandinavica 153, 375-380.

McLean DA, Bangsbo J \& Saltin B (1999) Skeletal muscle interstitial glucose and lactate levels during exerise in humans determined by microdialysis. Journal of Applied Physiology (In the Press).

Marshall JM, Thomas T \& Turner L (1993) A link between adenosine, ATP-sensitive $\mathrm{K}^{+}$channels, potassium and muscle vasodilation in the rat in systemic hypoxia. Journal of Physiology 472, 1-9.

Mian R, Marshall J \& Kumar P (1990) Interactions between $\mathrm{K}^{+}$and $\beta_{2}$-adrenoreceptors in determining muscle vasodilation induced in rat by systemic hypoxia. Experimental Physiology 75, $407-410$.

Moncada S (1992) The L-arginine: nitric oxide pathway. Acta Physiologica Scandinavica 145, 201-227.

Nitsch J, Steinbeck G \& Luderitz B (1980) Comparison of myocardial potassium and thallium flux as studied by tracer methods. Clinical Cardiology 3, 188-191.

Palsmeier RK \& Lunte CE (1994) Microdialysis sampling in tumor and muscle: Study of the disposition of 3-amino-1,2,4benzotriazine-1,4-di-N-oxide (SR 4233). Life Sciences 55, 815-825.

Piiper J, Pendergast DR, Marconi C, Meyer M, Heisler N \& Cerretelli P (1985) Blood flow distribution in dog gastrocnemius at rest and during stimulation. Journal of Applied Physiology 58, 2068-2074.

Roach RC, Koskolou MD, Calbet JAL \& Saltin B (1999) Arterial $\mathrm{O}_{2}$ content and tension in the regulation of cardiac output and leg blood flow during exercise in humans. American Journal of Physiology 276, H438-H445.

Rosdahl H, Hamrin K, Ungerstedt U \& Henriksson J (1998) Metabolite levels in human skeletal muscle and adipose tissue studied with microdialysis at low perfusion flow. American Journal of Physiology 274, E936-E945.

Rosdahl H, Ungerstedt U, Jorfeldt L \& Henriksson J (1993) Interstitial glucose and lactate balance in human skeletal muscle and adipose tissue studied by microdialysis. Journal of Physiology 471, 637-657.

Rådegran G, Pilegaard H, Nielsen JJ \& Bangsbo J (1998) Microdialysis ethanol removal reflects probe recovery rather 
than local blood flow in skeletal muscle. Journal of Applied Physiology 85, 751-757.

Rådegran J \& Satin B (1997) Role of nitric oxide for skeletal muscle blood flow regulation. Journal of Vascular Research 34, Suppl. 1, 33.

Scheller D \& Kolb J (1991) The internal reference technique in microdialysis: a practical approach to monitoring dialysis efficiency and to calculating tissue concentration from dialysate samples. Journal of Neuroscience Methods 40, $31-38$.

Skinner MR \& Marshall JM (1996) Studies on the roles of ATP, adenosine and nitric oxide in mediating muscle vasodilation induced in the rat by acute systemic hypoxia. Journal of Physiology 495, 553-560.
Smith GL, Austin C, Crichton C \& Wray S (1998) A review of the actions and control of intracellular $\mathrm{pH}$ in vascular smooth muscle. Cardiovascular Research 38, 316-331.

Stein CM, Brown N, Vaughan DE, Lang CC \& Wood AJ (1998) Regulation of local tissue-type plasminogen activator release by endothelium and endothelium-independent agonists in human vasculature. Journal of the American College of Cardiology 32, $117-122$.

Vallance P, Collier J \& Moncada S (1989) Effects of endotheliumderived nitric oxide on peripheral arteriolar tone in man. Lancet 2, 997-1000.

Vyskoãl F, Hnik P, Rehfeldt H, Vejsada R \& Ujec E (1983) The measurement of $\mathrm{K}^{+}$concentration changes in human muscles during volitional contractions. Pflügers Archiv 399, 325-327. 